\title{
COVID-19 infection in pregnancy: a single center experience with 75 cases
}

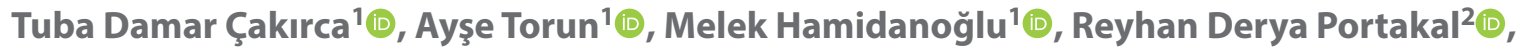 \\ Merhamet Ölç̧en ${ }^{2}$ (D), Gökhan Çakırca ${ }^{3}$, Murat Haksever ${ }^{4}$ (D) \\ ${ }^{1}$ Department of Infectious Diseases and Clinical Microbiology, Sanliurfa Training and Research Hospital, Sanliurfa, Turkey \\ ${ }^{2}$ Department of Chest Diseases, Sanliurfa Training and Research Hospital, Sanliurfa, Turkey \\ ${ }^{3}$ Department of Biochemistry, Sanliurfa Mehmet Akif Inan Training and Research Hospital, Sanliurfa, Turkey \\ ${ }^{4}$ Department of Obstetrics and Gynecology, Sanliurfa Training and Research Hospital, Sanliurfa, Turkey
}

\begin{abstract}
Objectives: This study aimed to summarize the clinical features, maternal, fetal, and perinatal outcomes of severe acute respiratory syndrome coronavirus 2 (SARS-CoV-2) proven infections of pregnancies.

Material and methods: This retrospective single center study was conducted on 75 pregnant patients diagnosed of coronavirus disease 2019 (COVID-19). Demographic characteristics, clinical courses, laboratory and radiological findings, and maternal and perinatal outcomes were analyzed using medical records.

Results: Of the 75 pregnant women infected with COVID-19, 49 had mild infections. The most common initial symptoms were myalgia (61.4\%), cough (57.9\%), headache (50.9\%), and dyspnea (49.1\%). More than half of the patients $(57.3 \%)$ on admission were in their third trimester. Three patients had pre-existing chronic illnesses (hypothyroidism, asthma and rheumatoid arthritis) and three patients had gestational diabetes. There were two cases admitted to intensive care unit, one of whom was due to COVID-19 infection. No maternal mortality was recorded. The mode of delivery was a cesarean section in 20 cases among the 35 labors. Six gestations ended in a miscarriage and 11 women gave birth prematurely. One stillbirth occurred at the 38th week of gestation. Among 37 neonates, 14 necessitated admission to neonatal intensive care unit. Neonatal mortality, congenital malformation, and mother to child transmission were not seen in the newborns.

Conclusions: The results of our study suggest that the clinical course of COVID-19 infection in pregnant women was mostly asymptomatic/mild. There was also no evidence of vertical transmission of COVID-19 infection.
\end{abstract}

Key words: COVID-19; pregnancy; perinatal outcome; SARS-CoV-2; vertical transmission

Ginekologia Polska 2022; 93, 5: 410-415

\section{INTRODUCTION}

The new coronavirus disease (COVID-19), which emerged in late 2019, is spreading rapidly all over the world [1]. The clinical spectrum of this disease ranges from non-symptomatic infection or flu-like illness to organ dysfunction and respiratory failure even resulting in death [2]. It has been reported that the course of the disease is more severe in vulnerable populations such as the elderly and immunocompromised people [3, 4].

Previous coronavirus outbreaks, severe acute respiratory syndrome (SARS) or Middle East respiratory syndrome (MERS), have led to serious consequences and high fatality rates in pregnant women and their fetuses and neonates
$[5,6]$. Furthermore, pregnant women are prone to respiratory illnesses due to anatomical and physiological changes (e.g., reduced functional residual capacity, increased edema in the upper respiratory tract, elevated diaphragm, and impaired immunity) in pregnancy $[7,8]$. In addition, the immaturity of the innate and adaptive immune systems in the fetus/newborn makes them vulnerable to infections [9]. Considering this information, the current COVID-19 outbreak poses a potential threat for pregnant women and newborns. At present, data about the effect of COVID-19 infection on pregnancy is still sparse, thus limiting the clinical management algorithms and effective treatment of pregnant women infected with COVID-19. Therefore, more

\footnotetext{
Corresponding author:

Tuba Damar Çakırca

Department of Infectious Diseases and Clinical Microbiology, Sanliurfa Training and Research Hospital, Sanliurfa, Turkey

e-mail:dr.tubadamar@gmail.com
} 
information is needed regarding the effect of the disease on pregnant women.

\section{Objectives}

This study thus is aimed to summarize the clinical manifestations, maternal, fetal, and neonatal outcomes of pregnant women infected with COVID-19.

\section{MATERIAL AND METHODS}

This retrospective single center study included 75 pregnant women, who were hospitalized with confirmed SARS-CoV-2 infection at the Sanliurfa Training and Research Hospital between April and August 2020. Sanliurfa Training and Research Hospital is a tertiary referral center that provides services in almost all medical departments, especially in pediatrics, obstetrics, and gynecology. The definitive diagnosis of the patients was made based on a positive real-time polymerase chain reaction (RT-PCR) test of nasopharyngeal swab specimens. Patients with suspected COVID-19 infection but laboratory-non-confirmed cases excluded from the study.

The demographic features, clinical characteristics, laboratory and radiological findings, administered therapies, and outcomes data of the patients were analyzed retrospectively using the hospital record system. The patients were categorized as asymptomatic, mild, severe and critically ill based on the disease severity [10]. After discharge, patients were called by phone and asked for any complaints or whether pregnancy is ongoing, the mode of delivery, maternal, and neonatal outcome. This study was approved by the Turkish Ministry of Health and Harran University School of Medicine Ethics Committee Commission (protocol number HRU/20.16.05)

Statistical analyses were done using SPSS version 21.0 (Chicago IL, USA). Data are presented as mean \pm standard deviation, median (minimum-maximum), n (\%) or n/N (\%), where $\mathrm{N}$ is the total number of patients with available data.

\section{RESULTS}

A total of 75 pregnant women with COVID-19 infection were involved in this study. Baseline characteristics and clinical features of COVID-19 cases are presented in Table 1. The median age of the women was 29 (range, 18 to 45) and gestational age at presentation ranged from 6 to 38 weeks (median, 28 weeks). Twelve cases (16\%) were infected with SARS-CoV-2 in the first trimester; 20 (26.7\%) in the second, and $43(57.3 \%)$ in the third trimester. Three women had preexisting chronic illnesses (hypothyroidism, asthma, and rheumatoid arthritis, respectively); while 3 had gestational diabetes. Forty-eight of 64 cases had epidemiological contact history. Myalgia (61.4\%), cough (57.9\%), headache (50.9\%), and dyspnea (49.1\%) were the most common symp-
Table 1. Maternal characteristics and clinical features of COVID-19 cases

Maternal characteristics

All patients $(n=75)$

Age

$29(18-45)$

Gestational age at presentation, week

$28(6-38)$

$\leq 12$ week (first trimester), $\mathrm{n}(\%)$

$12(16)$

13-27 week (second trimester), $\mathrm{n}(\%)$

$20(26.7)$

$\geq 28$ week (third trimester), $\mathrm{n}(\%)$

$43(57.3)$

Gravidity

$3(1-12)$

Parity

$2(0-9)$

Living children

$2(0-9)$

Comorbidities

Gestational Diabetes, n (\%)

Hypothyroidism, $n(\%)$

1 (1.3)

Asthma, $\mathrm{n}(\%)$

Rheumatoid Arthritis, n (\%)

\section{Epidemiological contact history}

Yes, $\mathrm{n} / \mathrm{N}(\%)$

$48 / 64$ (75)

No, $\mathrm{n} / \mathrm{N}(\%)$

$16 / 64(25)$

\section{Symptoms on admission}

Fever, $\mathrm{n} / \mathrm{N}(\%)$

21/57 (36.8)

Headache, $\mathrm{n} / \mathrm{N}(\%)$

29/57 (50.9)

Myalgia, $\mathrm{n} / \mathrm{N}(\%)$

$35 / 57(61.4)$

Sore throat, $\mathrm{n} / \mathrm{N}(\%)$

$18 / 57(31.6)$

Cough, $\mathrm{n} / \mathrm{N}(\%)$

$33 / 57(57.9)$

Dyspnea, $\mathrm{n} / \mathrm{N}(\%)$

28/57 (49.1)

Chest pain, n/N (\%)

21/57 (36.8)

Rhinorrhea/Nasal stuffiness, n/N (\%)

$6 / 57(10.5)$

Anosmia, n/N (\%)

$11 / 57(19.3)$

Ageusia, $\mathrm{n} / \mathrm{N}(\%)$

$10 / 57(17.5)$

Nausea/Vomiting, $\mathrm{n} / \mathrm{N}(\%)$

$7 / 57(12.3)$

Diarrhea, n/N (\%)

$8 / 57$ (14)

Conjunctivitis, $\mathrm{n} / \mathrm{N}(\%)$

$1 / 57(1.8)$

\section{Disease Severity}

Asymptomatic, $\mathrm{n}(\%)$

9 (12)

Mild, $\mathrm{n}(\%)$

$49(65.3)$

Moderate, $\mathrm{n}(\%)$

$16(21.3)$

Severe, $\mathrm{n}(\%)$

Critical, $\mathrm{n}(\%)$

$0(0)$

\section{Treatment}

\section{Hydroxychloroquine, $n(\%)$}

$24(32)$

Lopinavir/ritonavir, n (\%)

$12(16)$

Azithromycin, $n$ (\%)

$10(13.3)$

Low molecular weight heparin, $n(\%)$

$64(85.3)$

Other ampirical antibiotics, $\mathrm{n}(\%)$

$56(74.7)$

Data are presented as median (minimum-maximum), $\mathrm{n}(\%)$ or $\mathrm{n} / \mathrm{N}(\%)$, where $\mathrm{N}$ is the total number of patients with available data 
Table 2. Maternal laboratory and radiological findings on admission Laboratory Results All patients $(n=75)$

Leukocyte, $\times 10^{3} / \mu \mathrm{L}$

$7.13(3.38-14.29)$

Leukocytosis (>10 $\left.\times 10^{3} / \mu \mathrm{L}\right)$

$15 / 75(20 \%)$

Leukopenia $\left(<4 \times 10^{3} / \mu \mathrm{L}\right)$

$2 / 75(2.7 \%)$

Neutrophil, $\times 10^{3} / \mu \mathrm{L}$

$5.43(1.16-11.75)$

Neutrophilia $\left(>6.9 \times 10^{3} / \mu \mathrm{L}\right)$

$20 / 75(26.7 \%)$

Lymphocyte, $\times 10^{3} / \mu \mathrm{L}$

$1.33(0.58-2.69)$

Lymphopenia $\left(<1 \times 10^{3} / \mu \mathrm{L}\right)$

$16 / 75(21.3 \%)$

Monocyte, $\times 10^{3} / \mu \mathrm{L}$

$0.47(0.20-1.73)$

Platelet, $\times 10^{3} / \mu \mathrm{L}$

$220(78-455)$

Thrombocytopenia $\left(<150 \times 10^{3} / \mu \mathrm{L}\right)$

10/75 (13.3\%)

$\mathrm{Hb}[\mathrm{g} / \mathrm{dL}]$

$11.7(7.8-14.5)$

Hct (\%)

Urea [mg/dL]

$34.3(25.7-42.1)$

$13.9(7.1-28.1)$

Creatinine $[\mathrm{mg} / \mathrm{dL}]$

$0.60(0.36-0.91)$

AST [U/L]

$23.8(7.7-110.7)$

Elevated AST (> 40, U/L)

$17 / 75$ (22.7\%)

ALT [U/L]

$15.9(5.2-94.4)$

Elevated ALT (> 41, U/L)

10/75 (13.3\%)

GGT [U/L]

$11.0(3.0-145)$

ALP [U/L]

90 (39-231)

LDH [U/L]

227 (128-909)

Total bilirubin [mg/dL]

$0.30(0.15-1.66)$

Direct bilirubin [mg/dL]

$0.13(0.09-1.48)$

Albumin [g/dL]

$3.68(2.90-4.84)$

Total protein [g/dL]

$6.71(5.31-8.15)$

CRP [mg/L]

$7.63(0.60-166.73)$

Elevated CRP (> $5 \mathrm{mg} / \mathrm{L}$ )

Procalcitonin $[\mathrm{ng} / \mathrm{mL}]$

48/73 (65.8\%)

$0.05(0.02-0.24)$

D-Dimer $[\mu \mathrm{g} / \mathrm{mL}]$

$0.89(0.15-7.34)$

Fibrinogen [mg/dL]

452.3 (121.6-825)

PT, sn

$11.5(9.6-13.7)$

INR

$0.99(0.84-1.17)$

Blood type

$A(+), n / N(\%)$

22/72 (30.6\%)

$B(+), n / N(\%)$

10/72 (13.9\%)

$A B(+), n / N(\%)$

6/72 (8.3\%)

$\mathrm{O}(+), \mathrm{n} / \mathrm{N}(\%)$

24/72 (33.3\%)

$\mathrm{A}(-), \mathrm{n} / \mathrm{N}(\%)$

$4 / 72(5.6 \%)$

$B(-), n / N(\%)$

$1 / 72(1.4 \%)$

$\mathrm{AB}(-), \mathrm{n} / \mathrm{N}(\%)$

0/72 (0\%)

$0(-), n / N(\%)$
Table 2 cont. Maternal laboratory and radiological findings on admission

Laboratory Results

All patients $(n=75)$

Radiological Findings

Chest $\mathrm{X}$-ray findings

Normal, $\mathrm{n} / \mathrm{N}(\%)$

$17 / 42(40.5 \%)$

Infiltrated, n/N (\%)

25/42 (59.5\%)

Chest CT scan

Normal, n/N (\%)

$10 / 25(40 \%)$

Evidence of COVID-19 pneumonia, n/N (\%) 15/25 (60\%)

ALP — alkaline phosphatase; ALT — alanine aminotransferase; AST — aspartate aminotransferase; COVID-19 - coronavirus disease 2019; CRP - C-reactive protein GGT - gamma-glutamyl transferase; $\mathrm{Hb}$ - hemoglobin; $\mathrm{Hct}$ - hematocrit; INR - international normalized ratio; LDH - lactate dehydrogenase; PT - prothrombin time; Data are presented as median (minimum-maximum), $\mathrm{n}(\%)$ or $\mathrm{n} / \mathrm{N}(\%)$, where $\mathrm{N}$ is the total number of patients with available data

toms on admission in 57 cases with available data. Of the 75 confirmed cases, 49 had mild infection and 16 had moderate infection. Nine cases were asymptomatic and had been tested due to exposure history. Only one woman had severe infection and was admitted to the intensive care unit (ICU) but did not require mechanical ventilation. Another patient who had moderate COVID-19 infection was admitted to the ICU due to complication of gestational diabetes. Sixty-six patients were given empirical antibiotic treatment. Hydroxychloroquine and Lopinavir/ritonavir were administered in 24 and 12 patients, respectively. Moderate and severe cases were given oxygen support and 64 out of 75 patients received low molecular weight heparin (LMWH).

The laboratory and radiological results of patients on admission are presented in Table 2. Lymphopenia and thrombocytopenia were present in 16 and 10 patients, respectively. Ten out of the 75 patients had increased alanine aminotransferase and 17 had increased aspartate aminotransferase. Elevated CRP was present in 48 out of the 73 patients. The most frequent blood type was $0 \mathrm{Rh}$ (+). A total of 42 out of the 75 patients had chest X-ray screening, and 25 of them had infiltration in lungs. Evidence of COVID-19 pneumonia was shown in 15 of the 25 cases who underwent chest computed tomography (CT) imaging.

Maternal, pregnancy, and neonatal outcomes of cases are presented in Table 3. Among the 75 patients with COVID-19 infection, 63 (84\%) had known pregnancy outcome status. Regarding maternal outcomes, no mortality was reported, two women (2.7\%) required admission to ICU. None of them were mechanically ventilated. The first case admitted to the ICU was a 23-year-old woman who had severe COVID-19 infection. She had no comorbid conditions and obstetric complication previously. She presented a 7-day-history of cough, dyspnea, and chest pain 
Table 3. Maternal, pregnancy and neonatal outcomes of cases

All patients

$(n=75)$

\begin{tabular}{|l|c|}
\hline Maternal Outcome & \\
\hline Maternal mortality, $\mathrm{n}(\%)$ & $2(0)$ \\
\hline ICU admission, $\mathrm{n}(\%)$ & \\
\hline Pregnancy Outcome & \\
\hline Delivery status & $22 / 63(34.9)$ \\
\hline Pregnancy Ongoing, $\mathrm{n} / \mathrm{N}(\%)$ & $15 / 63(23.8)$ \\
\hline Natural delivery, $\mathrm{n} / \mathrm{N}(\%)$ & $20 / 63(31.7)$ \\
\hline Cesarean section, $\mathrm{n} / \mathrm{N}(\%)$ & $6 / 63(9.5)$ \\
\hline Abortion, $\mathrm{n} / \mathrm{N}(\%)$ & $34 / 35(97.1)$ \\
\hline Live birth (31 singletons and 3 set of twins) & $1 / 35(2.9)$ \\
\hline Stillbirth (1 singleton) & $11 / 35(31.4)$ \\
\hline Preterm labor & \\
\hline Neonatal Outcome & $2787.6 \pm 837.3$ \\
\hline Birth weight [g] & $3000(790-4050)$ \\
\hline Low birth weight, $\mathrm{n} / \mathrm{N}(\%)$ & $9 / 37(24.3)$ \\
\hline Neonatal ICU admission, $\mathrm{n} / \mathrm{N}(\%)$ & $14 / 37(37.8)$ \\
\hline Neonatal mortality, $\mathrm{n} / \mathrm{N}(\%)$ & $0 / 33(0)$ \\
\hline Congenital malformation, $\mathrm{n} / \mathrm{N}(\%)$ & $0 / 33(0)$ \\
\hline Neonatal SARS-CoV-2 positivity, $\mathrm{n} / \mathrm{N}(\%)$ & $0 / 8(0)$ \\
\hline
\end{tabular}

ICU - intensive care unit; SARS-CoV-2 - severe acute respiratory syndrome coronavirus 2; Data are presented as mean \pm standard deviation, median (minimum-maximum), $\mathrm{n}(\%)$ or $\mathrm{n} / \mathrm{N}(\%)$, where $\mathrm{N}$ is the total number of patients with available data

and a CT scan revealed diffuse ground-glass opacities with pulmonary consolidations in the bilateral lower lobes. She was tachypneic with a respiratory rate of 42 and administered continuous positive airway pressure (CPAP) therapy. She gave birth to a healthy child at the gestational age of 37 weeks. The patient was followed up in the hospital for thirteen days (including seven days in ICU) and was discharged with no complication. The second patient was a 36-year-old woman with gestational diabetes and required admission to the ICU due to the obstetric complication of diabetes mellitus. She was delivered of a $3800 \mathrm{~g}$ stillborn infant at the gestational age of 38 weeks. She had moderate COVID-19 infection and was discharged with no complication after fifteen days stay in hospital.

A total of 41 out of the 63 patients were delivered at the time of writing of the report. Of these 41 patients, 15 (23.8\%) had natural delivery and 20 (31.7\%) underwent a cesarean section. Six gestation ended in spontaneous abortion between 8 and 14 weeks.

There were 34 live births ( 31 singletons and three sets of twins that gave a total of 37 newborns) and one stillbirth among 35 deliveries. Of these, 24 were full term ( $>37$ weeks of gestation) and 11 were preterm at the gestational age ranging from 25 to 36 weeks. The mean birth weight of newborns was $2787.6 \pm 837.3 \mathrm{~g}$ and nine neonates had low birth weight $(<2500 \mathrm{~g})$. Among the 37 infants, 14 required admission to neonatal intensive care unit (NICU); six of them had transient tachypnea of newborn (TTN), five newborns who were suspected with congenital pneumonia received antibiotherapy and one of them needed CPAP therapy. A total of four preterm neonates were intubated for respiratory distress; three of them cured whereas one of them was shipped to another hospital. In total, 10 newborns discharged uneventfully, outcome data was unavailable in four. No congenital malformation or neonatal mortality was observed with available data. A nasopharangeal swab test was performed on 8 neonates and all results were negative. The breastmilk, cord blood, or amniotic fluid samples were not tested for SARS-CoV-2.

\section{DISCUSSION}

In this descriptive study, we report the findings of 75 SARS-CoV-2 PCR positive pregnant women. Most patients had mild infection and all of them discharged uneventfully. In our study population the rate of ICU admission was $2.7 \%$ indicating the course of SARS-CoV-2 infection during gestation was favorable.

Immune system changes arising during pregnancy can render the pregnant women vulnerable to the respiratory viral infections [11]. Reportedly, the pregnant individuals had more severe outcomes of SARS-CoV, MERS-CoV, and influenza infections [12-14]. Several reports were published on the course of COVID-19 infection during pregnancy [15-20]; but there are conflicting results. In some researches it has been found that the course of the illness in pregnant women was not worse than in non-pregnant women; whereas critically ill patients and deaths were also reported [15-17, 21-23]. In our study, the clinical course of pregnant patients was favorable. Maternal mortality or serious consequences were not seen.

As reported previously, despite of discrepancy in initial symptoms, most COVID-19 patients present with respiratory symptoms [24]. In our study the most seen symptoms on admission were myalgia, cough, headache, and dyspnea, respectively.

Recommendations for management of pregnant women infected with COVID-19 include antiviral treatment alongside supportive therapy and prophylaxis for venous thromboembolism. Antibacterial therapy is also recommended in case of suspicion of secondary bacterial infection [25, 26]. After the first case of COVID-19 was detected in Turkey on the $10^{\text {th }}$ of March 2020, The Turkish Ministry of Health established a scientific committee and published interim guidelines, which updated regularly, on the management of COVID-19 patients. Treatment protocols for study popu- 
lation were chosen according to guidelines and severity of infection [27]. COVID-19 therapy (Hydroxychloroquine and Lopinavir/ritonavir) was administered to approximately half of our patients, and 64 patients received LMWH. A total of 66 out of 75 patients were given empirical antibiotic therapy.

According to our study, laboratory results included neutrophilia, lymphopenia, an increase in CRP, elevated AST, and $A L T$, which were in consistency as recently reported $[16,17]$.

There are conflicting results on the association between blood type and COVID-19 infection. Some researchers found that blood type A was associated with a higher risk ofCOVID-19 infection [28, 29]. On the other hand, Mendy et al. [30], reported blood type 0 was more frequent in COVID-19 patients. In another study, blood group B was the most seen type in these patients [31]. Our study revealed blood type 0 was more common among COVID-19 infected patients.

More than half of our patients had a chest X-ray, 59.5\% of whom had infiltration. On the other hand, it has been claimed that CT scan is more efficient and has a pivotal role in the diagnosis of COVID-19 pneumonia with a higher sensitivity than in chest X-rays [32]. A recent study by Guan et al. [33], also depicted that typical CT imaging findings of $76.4 \%$ patients were proven by a COVID-19 infection. A CT scan was performed on one of three of our patients and $60 \%$ of whom had evidence of COVID-19 pneumonia. Radiological methods may be useful to verify the diagnosis in patients with suspected COVID-19.

A review by Elshafeey et al. [19], reported the clinical features and outcomes of 385 pregnant women, 175 of whom delivered by cesarean section. In the present study, 41 of the 63 patients whom pregnancy status known, gave birth during the writing of this report and the mode of delivery was cesarean section in 20 cases. Fetal distress, intrauterine fetal death, previous cesarean section, and early membrane rupture were the indications for cesarean section. Higher rates of preterm labor were reported in some previous studies $[20,34]$ however, a review based on 116 COVID-19 patients by Yan et al. [35], reported that the incidence of spontaneous preterm birth is not increased. In this study, 11 of the 35 patients were delivered prematurely. Nine of them had no gestational complication history or maternal comorbidities previously, whereas one had gestational diabetes, one had hypothyroidism, and another woman had been using enoxaparin for the risk of premature birth.

There were 34 live births ( 31 singletons and 3 sets of twins) and one stillbirth, but the cause of fetal death was not related to COVID-19 infection. The mother had gestational diabetes during pregnancy and required admission to ICU due to the obstetric complication of diabetes mellitus. Despite absence of neonatal mortality and congenital malformations, we report a high rate of NICU admission
(37.8\%) compared to the previous publications [19, 36]. Regarding the neonates required NICU admission, 10 of them were premature babies and among these babies nine had low birth weights.

Another challenging issue that remains dubious is whether there is a vertical transmission in COVID-19 infection. Excessive studies have revealed no evidence of intrauterine mother to child transmission $[11,18,20,22,34$, 35]. On the other hand, case reports by Wang et al. [37], and Alzamora et al. [38], showed SARS-CoV-2 positivity on nasopharyngeal swab tests of two neonates. Besides, Zamaniyan et al. [39], presented a case report, in which nasopharyngeal swab and amniotic fluid tested positive for SARS-CoV-2. Therefore, based on this information we cannot rule out the probability of vertical transmission. We performed a nasopharyngeal swab test for only eight neonates who were admitted to the NICU, and all results were negative for SARS-CoV-2.

The strength of our study is based on reporting a high number of PCR confirmed cases from a single center. However, the study has some limitations. First, the study was conducted retrospectively and there were missing data. Second, there are ongoing pregnancies that were an obstacle to evaluate the outcome of all patients with COVID-19 infection. Third, only a few newborns were tested for SARS-CoV-2 and no direct tests for breast milk, cord blood, or amniotic fluid were done to assess possible mother to fetal transmission.

\section{CONCLUSIONS}

In conclusion, the clinical course of COVID-19 infection in pregnant women was favorable. All patients involved in the study were discharged uneventfully. We cannot rule out mother to child transmission with available data, therefore further studies are needed to answer the questions about possibility of vertical transmission.

\section{Acknowledgments}

We thank Dr. Tuğba Erat (Department of Pediatric Infectious Diseases, Sanlıurfa Training and Research Hospital, Sanliurfa, Turkey) for assistance in data acquisition.

\section{Conflicts of interest}

All authors declare no conflict of interest.

\section{REFERENCES}

1. World Health Organization. Coronavirus Disease 2019 (Covid-19) Situation Report - 88. https://www.who.int/emergencies/diseases/novel-coronavirus-2019/situation-reports/ (07.10.2020).

2. Chen $N$, Zhou M, Dong $X$, et al. Epidemiological and clinical characteristics of 99 cases of 2019 novel coronavirus pneumonia in Wuhan, China: a descriptive study. Lancet. 2020; 395(10223): 507-513, doi: 10.1016/S0140-6736(20)30211-7, indexed in Pubmed: 32007143. 
3. Zhou F, Yu T, Du R, et al. Clinical course and risk factors for mortality of adult inpatients with COVID-19 in Wuhan, China: a retrospective cohort study. Lancet. 2020; 395(10229): 1054-1062, doi: 10.1016/S01406736(20)30566-3, indexed in Pubmed: 32171076.

4. Fishman JA, Grossi PA. Novel Coronavirus-19 (COVID-19) in the immunocompromised transplant recipient: \#Flatteningthecurve. Am J Transplant. 2020; 20(7): 1765-1767, doi: 10.1111/ajt.15890, indexed in Pubmed: 32233057.

5. Wong $\mathrm{S}$, Chow K, Leung T, et al. Pregnancy and perinatal outcomes of women with severe acute respiratory syndrome. Am J Obstet Gynecol. 2004; 191(1): 292-297, doi: 10.1016/j.ajog.2003.11.019.

6. Alfaraj SH, Al-Tawfiq JA, Memish ZA. Middle east respiratory syndrome coronavirus (MERS-CoV) infection during pregnancy: report of two cases \& review of the literature. J Microbiol Immunol Infect. 2019; 52(3): 501-503, doi: 10.1016/j.jmii.2018.04.005, indexed in Pubmed: 29907538.

7. Tan EK, Tan EL. Alterations in physiology and anatomy during pregnancy. Best Pract Res Clin Obstet Gynaecol. 2013; 27(6): 791-802, doi: 10.1016/j. bpobgyn.2013.08.001, indexed in Pubmed: 24012425.

8. Dashraath P, Wong JL, Lim MX, et al. Coronavirus disease 2019 (COVID-19) pandemic and pregnancy. Am J Obstet Gynecol. 2020; 222(6): 521-531, doi: 10.1016/j.ajog.2020.03.021, indexed in Pubmed: 32217113.

9. van Well GTJ, Daalderop LA, Wolfs T, et al. Human perinatal immunity in physiological conditions and during infection. Mol Cell Pediatr. 2017; 4(1): 4, doi: 10.1186/s40348-017-0070-1, indexed in Pubmed: 28432664.

10. Diagnosis and treatment protocol for novel coronavirus pneumonia (trial version 7). Chin Med J (Engl). 2020; 133(9): 1087-1095, doi: 10.1097/CM9.0000000000000819, indexed in Pubmed: 32358325.

11. Schwartz DA. An analysis of 38 pregnant women with COVID-19, their newborn infants, and maternal-fetal transmission of SARS-CoV-2: maternal coronavirus infections and pregnancy outcomes. Arch Pathol Lab Med. 2020; 144(7): 799-805, doi: 10.5858/arpa.2020-0901-SA, indexed in Pubmed: 32180426.

12. Schwartz DA, Graham AL. Potential maternal and infant outcomes from (wuhan) coronavirus 2019-ncov infecting pregnant women: lessons from SARS, MERS, and other human coronavirus infections. Viruses. 2020; 12(2): 194, doi: 10.3390/v12020194, indexed in Pubmed: 32050635.

13. Rasmussen $S A$, Jamieson DJ, Uyeki TM. Effects of influenza on pregnant women and infants. Am J Obstet Gynecol. 2012; 207(Suppl 3): S3-S8, doi: 10.1016/j.ajog.2012.06.068, indexed in Pubmed: 22920056.

14. Silasi M, Cardenas I, Kwon JY, et al. Viral infections during pregnancy. Am J Reprod Immunol. 2015; 73(3): 199-213, doi: 10.1111/aji.12355, indexed in Pubmed: 25582523.

15. Chen $L$, Li Q, Zheng $D$, et al. Clinical characteristics of pregnant women with covid-19 in wuhan, china. N Engl J Med. 2020; 382(25): e100, doi: 10.1056/NEJMc2009226, indexed in Pubmed: 32302077.

16. Sahin D, Tanacan A, Erol SA, et al. A pandemic center's experience of managing pregnant women with COVID-19 infection in Turkey: a prospective cohort study. Int J Gynaecol Obstet. 2020; 151(1): 74-82, doi: 10.1002/ijgo.13318, indexed in Pubmed: 32682342

17. Chen H, Guo J, Wang C, et al. Clinical characteristics and intrauterine vertical transmission potential of COVID-19 infection in nine pregnant women: a retrospective review of medical records. Lancet. 2020; 395(10226): 809-815, doi: 10.1016/S0140-6736(20)30360-3, indexed in Pubmed: 32151335.

18. Chen Y, Bai J. Maternal and infant outcomes of full-term pregnancy combined with COVID-2019 in Wuhan, China: retrospective case series. Arch Gynecol Obstet. 2020; 302(3):545-551, doi: 10.1007/s00404-020-055738, indexed in Pubmed: 32696241.

19. Elshafeey F, Magdi R, Hindi N, et al. A systematic scoping review of COVID-19 during pregnancy and childbirth. Int J Gynaecol Obstet. 2020; 150(1): 47-52, doi: 10.1002/ijgo.13182, indexed in Pubmed: 32330287.

20. Di Mascio D, Khalil A, Saccone G, et al. Outcome of coronavirus spectrum infections (SARS, MERS, COVID-19) during pregnancy: a systematic review and meta-analysis. Am J Obstet Gynecol MFM. 2020; 2(2): 100107, doi: 10.1016/j.ajogmf.2020.100107, indexed in Pubmed: 32292902.

21. Breslin N, Baptiste C, Gyamfi-Bannerman C, et al. Coronavirus disease 2019 infection among asymptomatic and symptomatic pregnant women: two weeks of confirmed presentations to an affiliated pair of
New York City hospitals. Am J Obstet Gynecol MFM. 2020; 2(2): 100118 , doi: 10.1016/j.ajogmf.2020.100118, indexed in Pubmed: 32292903.

22. Karimi-Zarchi M, Neamatzadeh $H$, Dastgheib SA, et al. Vertica transmission of coronavirus disease 19 (COVID-19) from infected pregnant mothers to neonates: a review. Fetal Pediatr Pathol. 2020; 39(3): 246-250, doi: 10.1080/15513815.2020.1747120, indexed in Pubmed: 32238084 .

23. Hantoushzadeh $S$, Shamshirsaz AA, Aleyasin A, et al. Maternal death due to COVID-19. Am J Obstet Gynecol. 2020; 223(1): 109.e1-109.e16, doi: 10.1016/j.ajog.2020.04.030, indexed in Pubmed: 32360108.

24. Jiang $F$, Deng $L$, Zhang $L$, et al. Review of the clinical characteristics of coronavirus disease 2019 (COVID-19). J Gen Intern Med. 2020; 35(5): 1545-1549, doi: 10.1007/s11606-020-05762-W, indexed in Pubmed: 32133578.

25. Liang H, Acharya G. Novel corona virus disease (COVID-19) in pregnancy: what clinical recommendations to follow? Acta Obstet Gynecol Scand. 2020; 99(4): 439-442, doi: 10.1111/aogs.13836, indexed in Pubmed: 32141062.

26. Thachil J, Tang N, Gando S, et al. ISTH interim guidance on recognition and management of coagulopathy in COVID-19. J Thromb Haemost. 2020; 18(5): 1023-1026, doi: 10.1111/jth.14810, indexed in Pubmed: 32338827.

27. COVID-19 Bilgilendirme Platformu . https://covid19.saglik.gov.tr/TR66301/covid-19-rehberi.html// (09.10.2020).

28. Zietz M, Zucker J, Tatonetti NP, et al. Testing the association between blood type and COVID-19 infection, intubation, and death. medRxiv. 2020, doi: 10.1101/2020.04.08.20058073, indexed in Pubmed: 32511586.

29. Göker H, Aladağ Karakulak E, Demiroğlu H, et al. The effects of blood group types on the risk of COVID-19 infection and its clinical outcome. Turk J Med Sci. 2020; 50(4): 679-683, doi: 10.3906/sag-2005-395, indexed in Pubmed: 32496734

30. Mendy A, Keller JL, Apewokin S, et al. Is blood type associated with COVID-19 severity? medRxiv. 2020, doi: 10.1101/2020.08.11.20172676, indexed in Pubmed: 32817977.

31. Latz CA, DeCarlo C, Boitano L, et al. Blood type and outcomes in patients with COVID-19. Ann Hematol. 2020; 99(9): 2113-2118, doi: 10.1007/s00277-020-04169-1, indexed in Pubmed: 32656591.

32. Liu H, Liu F, Li J, et al. Clinical and CT imaging features of the COVID-19 pneumonia: Focus on pregnant women and children. J Infect. 2020; 80(5): e7-e13, doi: 10.1016/j.jinf.2020.03.007, indexed in Pubmed: 32171865.

33. Guan WJ, Ni ZY, Hu Y, et al. China Medical Treatment Expert Group for Covid-19. Clinical characteristics of coronavirus disease 2019 in China. N Engl J Med. 2020; 382(18): 1708-1720, doi: 10.1056/NEJMoa2002032, indexed in Pubmed: 32109013.

34. Li N, Han L, Peng M, et al. Maternal and neonatal outcomes of pregnant women with COVID-19 pneumonia: a case-control study. Clin Infect Dis. 2020; 71(16): 2035-2041, doi: 10.1101/2020.03.10.20033605, indexed in Pubmed: 32249918.

35. Yan J, Guo J, Fan C, et al. Coronavirus disease 2019 in pregnant women: a report based on 116 cases. Am J Obstet Gynecol. 2020; 223(1): 111.e1111.e14, doi: 10.1016/j.ajog.2020.04.014, indexed in Pubmed: 32335053.

36. Juan J, Gil MM, Rong Z, et al. Effect of coronavirus disease 2019 (COVID-19) on maternal, perinatal and neonatal outcome: systematic review. Ultrasound Obstet Gynecol. 2020; 56(1): 15-27, doi: 10.1002/uog.22088, indexed in Pubmed: 32430957.

37. Wang S, Guo L, Chen L, et al. A case report of neonatal 2019 coronavirus disease in China. Clin Infect Dis. 2020; 71(15): 853-857, doi: 10.1093/cid/ciaa225, indexed in Pubmed: 32161941.

38. Alzamora MC, Paredes T, Caceres D, et al. Severe COVID-19 during pregnancy and possible vertical transmission. Am J Perinatol. 2020; 37(8): 861-865, doi: 10.1055/s-0040-1710050, indexed in Pubmed: 32305046.

39. Zamaniyan M, Ebadi A, Aghajanpoor S, et al. Preterm delivery, maternal death, and vertical transmission in a pregnant woman with COVID-19 infection. Prenat Diagn. 2020; 40(13): 1759-1761, doi: 10.1002/pd.5713, indexed in Pubmed: 32304114. 